\title{
Growth in a 'New World': Case Studies of Peer Leader Experiences in the STEPS Program for People With Acquired Brain Injury
}

\author{
Areti Kennedy, ${ }^{1}$ Benjamin Turner ${ }^{1}$ and Melissa Kendall ${ }^{1,2}$ \\ ${ }^{1}$ Acquired Brain Injury Outreach Service, Princess Alexandra Hospital, Queensland, Australia \\ ${ }^{2}$ Griffith Health Institute, Griffith University, Queensland, Australia.
}

\begin{abstract}
$B$ ackground: The Skills To Enable People and CommunitieS (STEPS) Program is a new information, support and skills program that aims to develop sustainable networks of support for individuals with acquired brain injury (ABI) and their families in communities throughout Queensland, Australia. The program adopts a selfmanagement approach and is delivered by trained peer and professional leaders. Aim: To explore the experiences of both peer and lay leaders in the delivery of the STEPS Skills Program and coordination of STEPS Network Groups. Method: A multiple qualitative case study design was utilised to explore the unique experiences of three trained STEPS Program Leaders. Data collection entailed in-depth semistructured interviews with participants and further incorporated routine STEPS Program Leader descriptive data. The data analysis involved a four-stage approach that included assembling the raw case data, constructing case records, producing case narratives and cross-case pattern analysis. Results: Case study narratives were produced to describe participant experiences with the STEPS Program. The cross-case pattern analysis revealed two dimensions of comparison. The first dimension describes the process by which participants became STEPS Program Leaders, while the second dimension reflects the growth outcomes experienced by participants through their involvement with the STEPS Program. Specific growth outcomes are described in relation to the following domains: 'expansion of social roles and skills', 'appreciation of life', 'interpersonal relationships and communication', 'confidence, personal strength and accomplishment' and 'growth in self as a person'. The results are also described with respect to a model that depicts the process of growth through STEPS Program delivery. Conclusion: Posttraumatic growth of peer leaders after brain injury can be facilitated within a therapeutic intervention such as the STEPS Program.
\end{abstract}

Keywords: posttraumatic growth, acquired brain injury, social rule, personal growth, community rehabilitation

A new body of literature on posttraumatic growth has emerged over recent years (Linley \& Joseph, 2004; McMillen, 1999, 2004). While much of this literature remains exploratory, the phenomenon of growth following adversity is not new and has historically been commented on by philosophers, theologians, social scientists and popular writers alike (Turner \& Cox, 2004). Posttraumatic growth has been defined as 'positive psychological changes experienced as a result of a struggle with highly challenging life circumstances' (Tedeschi $\&$ Calhoun, 2004, p. 1). One salient aspect of this definition is the fact that growth emerges not from the trauma itself but rather from the struggle with 
the aftermath of that trauma, including both positive and negative aspects of that struggle (Calhoun \& Tedeschi, 2004).

McMillen (1999) suggested that posttraumatic growth results from purposeful changes in life structure, changed views of others and the world, the receipt of needed support and the search for meaning in adversity. In reviewing the literature, McMillen (1999) found that studies reported that between 45 and $90 \%$ of their samples derived some benefit from adversities as diverse as natural, technological and criminal disasters, sexual assaults and health problems including AIDS, cancer and stroke.

Tedeschi and Calhoun (1996), as the founding theoretical proponents in this area, proposed a model of posttraumatic growth that posited five dimensions including new possibilities, relating to others, personal strength, spiritual change and appreciation of life. These areas of growth are purported to emerge through a process of constructive cognitive processes that include both intellectual and affective processing of new information (Calhoun \& Tedeschi, 2004) and result in the development of new schemas or the alteration of existing cognitive schemas (Tedeschi \& Calhoun, 2004). Important factors involved in the emergence of growth include aspects such as personality, managing emotion, support and disclosure, cognitive processing, rumination, wisdom and narrative development (Tedeschi \& Calhoun, 2004). Further to this, these authors proposed that social systems may be an important source of new or alternative schema. Indeed, they suggest that the characteristics of survivors and the nature of the circumstances faced are more important for growth than the mere passage of time (Tedeschi \& Calhoun, 1996)

The work of Tedeschi and Calhoun (2004) has been critically analysed and expanded on by numerous researchers and theorists (Aldwin \& Levenson, 2004; Campbell, Brunell, \& Foster, 2004; Janoff-Bulman, 2004; Maercker \& Zoellner, 2004; McMillen, 2004; Neimeyer, 2004; NolenHoeksema \& Davis, 2004; Pals \& McAdams, 2004; Wortman, 2004). Janoff-Bulman (2004) proposed that there were three primary processes underlying the outcomes proposed by Tedeschi and Calhoun (2004), namely, strength through suffering, psychological preparedness and existential reevaluation. Wortman (2004) proposed that while growth can be positive in one domain, it may be negative in another and it is the balance between these that influence the perception of growth. Further to this, however, Wortman (2004) suggested that growth may be facilitated when people are placed in situations where they successfully navigate tasks that enhance their competence.

When we consider the literature concerning populations of people with brain injury, the traditional focus has been on the description of pathological responses to trauma and injury. Indeed, it has only been in the past 5 years that the brain injury literature has reported posttraumatic growth beyond anecdotal accounts. In a small-scale preliminary study, McGrath and Linley (2006) measured growth in individuals who were recently injured and compared them to a group of individuals who had been injured for approximately 10 years, finding increased reports of posttraumatic growth in the group that had been injured longer, suggesting that growth developed over time. In a similar larger study, Powell, Ekin-Wood and Collin (2007) surveyed survivors of traumatic brain injury during the early period (1-3 years) and later period (10-12 years) and similarly found greater posttraumatic growth in the later group in all domains using the Posttraumatic Growth Inventory (Tedeschi \& Calhoun, 1996).

In a study of 60 stroke survivors, Gangstad, Norman and Barton (2009) found that posttraumatic growth was positively correlated with cognitive processing such as cognitive restructuring, downward comparison, resolution and denial. Hawley and Joseph (2008) found negative correlations between growth and anxiety/depression suggesting that anxiety was lower among those who showed greater growth. Contradictory to these findings, however, McGrath and Linley (2006) found a positive association between anxiety and growth where high levels of anxiety were evident with posttraumatic growth. Powell et al. (2007) found no differences between early and later groups on anxiety or depression, despite the increased growth in the later group. While these findings are mixed, there is the suggestion that growth can occur in the presence of at least moderate levels of psychological distress.

Perhaps the unique situation for explorations of posttraumatic growth after brain injury lies in the definitional reliance on cognitive processing and the likely impact that impaired cognition, such as reduced insight and awareness, might have on this process. Indeed, Powell et al. (2007) suggested that posttraumatic growth is insight- and awareness-related and the later group demonstrated greater growth that developed over time through rumination about the trauma.

Aldwin and Levenson (2004) suggested that work to date has failed to recognise the strong mediating role that coping is likely to play in the emergence of posttraumatic growth. It is when we 
consider this perspective that avenues for intervention in promoting posttraumatic growth become more salient. If growth can spontaneously emerge through successful coping efforts, then intervention can be a building block for growth through a focus on promoting successful coping. Intervention may then be able to provide a forum within which growth occurs and without which these opportunities for growth may not have arisen. Indeed, Turner and Cox (2004) suggested that healthcare provider contributions are needed in terms of recognising the worth of each individual, assisting them in envisioning a future, fostering active involvement of the individual in their own trajectory and celebrating changes to sense of self. In this regard, Powell et al. (2007), in their study of brain injury and posttraumatic growth, found that social support was the most important factor involved in fostering growth, followed by the development of personal skills, determination and a belief in self. Calhoun and Tedeschi (2004) suggested that perhaps the most fruitful area for future research is to consider the longer term consequences of developing a growth viewpoint among survivors. McMillen (2004) further suggested the need for increased specificity in explaining the role of social support and the broader sociocultural context within which growth occurs. It is with this focus that it was anticipated a locally developed initiative in Queensland, Australia may provide a forum within which posttraumatic growth could be fostered.

\section{Overview of the STEPS Program}

The Skills To Enable People and CommunitieS (STEPS) Program is a Queensland statewide information, support and skills program that was developed by the Acquired Brain Injury Outreach Service (ABIOS), which is based at the Princess Alexandra Hospital in Brisbane, Australia. The principal aim of the program is to establish sustainable networks of support for individuals with acquired brain injury (ABI) and their families in their local communities in Queensland. The program consists of the following phases: (1) the STEPS Skills Program; and (2) STEPS Network Groups.

The STEPS Skills Program is a structured, 6week group program (i.e., one 2-hour session per week for 6 weeks) that is led by trained leaders/facilitators. The STEPS Skills Program adopts a self-management approach in exploring the following three themes: (1) how I look after myself; (2) how I live in the community and (3) how I work with services. The first five sessions of the program include the provision of information and participation in group activities, which are contained in a participant workbook, on a range of topics relevant to these three themes. Specific topics addressed in the STEPS workbook include self-management, goal setting, understanding brain injury, stress management, relationships, developing a routine and participating in the community. The final session of the STEPS Skills Program is a community outing, which is the culmination of the group's planning for the outing during the preceding five sessions. During each session of the STEPS Skills Program, individuals are encouraged to share their experiences of life after brain injury in accordance with the workbook topics and activities. Since the inception of the program in 2006 to the end of 2010, approximately 609 people have completed the 6-week STEPS Skills Program across 84 sites throughout Queensland.

STEPS Network Groups are typically formed by individuals who have completed the initial 6week STEPS Skills Program. These groups provide an ongoing source of support for group participants. Groups are encouraged and supported to assume ownership of their STEPS Network Group, with key decisions such as the format of group meetings, topics for discussion and the frequency of group meetings all being made by the group itself. Consequently, each STEPS Network Group varies according to the expectations and preferences of individual group members. As of 2010, there were 19 active STEPS Network Groups throughout Queensland with an average monthly attendance of 130 participants.

\section{STEPS Leaders}

Both phases of the STEPS Program are coordinated centrally by health professionals at ABIOS (i.e., STEPS Program Staff). However, the delivery of the program occurs through locally trained volunteer leaders. STEPS Program Leaders include health professionals, other service providers (e.g., support workers), individuals with ABI (peer leaders) and family members (lay leaders). All leaders undergo a screening process and are required to complete a 2-day STEPS Leader Training Program. Co-leadership arrangements, which often involve peer-professional partnerships (i.e., health professional/service provider leader with peer/lay leader) are encouraged and fostered to enhance both participant and leader experiences. Between 2006 and 2010, approximately 220 people completed the STEPS Leader Training Program across 41 sites throughout Queensland. As of 2010, there were 75 active 
STEPS Leaders (i.e., leaders who have completed the leader training and are active in running STEPS Skills Programs or STEPS Network Groups) throughout Queensland, which includes 30 peer/lay leaders.

The role of a STEPS Skills Program leader is to facilitate the delivery of the structured STEPS Skills Program, as outlined in the STEPS Skills Program workbook. STEPS Skills Program leaders facilitate group discussions and coordinate group activities in relation to the various topics covered throughout the course of the 6-week program. All leaders are actively engaged in a formal support and supervision process with STEPS Program staff during delivery of the STEPS Skills Program, which entails weekly in-person or telephone contact. The role of a STEPS Network Group leader is to facilitate the activities of a STEPS Network Group. The specific role of a STEPS Network Group leader varies across sites due to the sense of group ownership, which is fostered and encouraged by STEPS Program staff. Consequently, the support provided by STEPS Program staff to Network Group leaders is tailored according to their specific needs and those of the group.

\section{Aims/Research Questions}

The principal aim of the present study was to explore the experiences of both peer and lay leaders in the delivery of the STEPS Skills Program and coordination of STEPS Network Groups. Specifically, the study addressed the following research questions: (1) How do peer and lay leaders describe their experiences of leading the STEPS Program? and (2) How does being a STEPS Program Leader influence the process of growth and positive change after brain injury?

\section{Method}

\section{Design}

The present study utilised a multiple qualitative case study design to explore the experiences of three trained STEPS Program Leaders. This approach was adopted to enable an in-depth exploration of the unique experiences of each of the leaders in the delivery of the STEPS Program.

\section{Participants}

Purposeful sampling was used to select suitable participants for the study according to the following criteria: (1) person with ABI or family member of person with ABI, (2) trained STEPS Program Leader and (3) led STEPS Skills
Program and/or STEPS Network Group in the previous 12-month period. Additionally, the location of participants (i.e., metropolitan vs. regional/rural) and cause of injury (i.e., traumatic vs. nontraumatic brain injury) were also considered in the selection of suitable participants to ensure a diverse case mix. Participants were required to have adequate cognitive and speech and language capabilities to engage in an in-depth semistructured interview. The detailed eligibility criteria for the study were employed to address the potential for sampling bias and thereby facilitate the selection of participants who were considered by the research team to be representative of the wider active leader base of the STEPS Program. Both peer and lay leaders were included to ensure representation of the scope of individuals who act as peer/lay leaders. In total, participants included two individuals with ABI (i.e., peer leaders) and one family caregiver of an individual with ABI (i.e., lay leader). A summary of each participant (i.e., excluding details of STEPS involvement, which is provided in the results section) is provided as follows. Participant names have been changed to maintain confidentiality.

Participant 1: Mr A is a 51-year-old male who sustained a traumatic brain injury (TBI) as a result of a motor vehicle accident. At the time of the study, Mr. A was 4 years and 9 months postinjury. After the onset of his injury, Mr A was hospitalised for 3 months, which included a stay of 2 months in an inpatient rehabilitation setting. $\mathrm{Mr} \mathrm{A}$ was discharged from hospital to home, in a regional location in Queensland, where he currently resides with the support of his wife and family. After discharge from hospital, Mr A received outpatient rehabilitation for a period of 14 months. While several attempts to return to work have been made, $\mathrm{Mr} \mathrm{A}$ has been unable to return to his pre-injury employment as a sporting club manager and is currently in receipt of a disability pension. Mr A reported that his cognitive functioning (e.g., poor short-term memory and planning and organisational difficulties) presents the most significant disturbance to his day-to-day functioning.

Participant 2: Ms B is a 25-year-old female who sustained an ABI as a result of stroke. At the time of the study, Ms B was 4 years and 6 months postinjury. Ms B was hospitalised for a period of 6 months following the onset of her injury, which included a stay of 5 months in an inpatient rehabilitation facility. Following hospital discharge, Ms B returned home to reside with her parents and siblings in metropolitan Brisbane. Ms B received outpatient rehabilitation for a period of 18 months, 
which included participating in a return to work process. She was successfully able to return to her pre-injury employment as a pharmacy assistant in a part-time capacity for a period of 12 months. However, due to injury-related and logistical considerations, Ms B was unable to continue parttime employment and she is currently in receipt of a disability pension. Ms B reported that her speech and language difficulties (i.e., expressive aphasia) and fatigue present the most significant disturbances to her day-to-day functioning.

Participant 3: Mrs C is a 49-year-old female caregiver of her son, who sustained a TBI as a result of a motor vehicle accident at the age of 20 years. At the time of the study, Mrs C's son was 6 years and 2 months postinjury. Mrs C's son was hospitalised for a period of 8 months after the onset of his injury, which included a stay of 4 months in an inpatient rehabilitation facility. Given that Mrs $\mathrm{C}$ and her family reside in a rural location, this period of hospitalisation and inpatient rehabilitation was provided in two separate metropolitan and regional locations. Furthermore, upon discharge from inpatient rehabilitation, Mrs C's son received outpatient rehabilitation at two separate regional locations for a period of 7 months before returning to his home town in a rural location of Queensland. Mrs C remained with her son during this time of hospitalisation and outpatient rehabilitation. She was required to take leave for a period of 12 months from her employment as a nurse to care for her son. After this time, Mrs C returned to work, initially on a part-time basis to enable her to continue to care for her son, then full-time eventually. While Mrs C's son has been unable to return to his pre-injury employment as an apprentice electrician, he has recently commenced work in a part-time capacity as a labourer. Mrs $\mathrm{C}$ reported that her son experiences difficulties controlling his emotions and behaviour, and with short-term memory, which continue to present the most significant disturbances to his day-to-day functioning.

\section{Data Collection}

The principal method of data collection entailed in-depth semistructured interviews, which were conducted by two members of the research team who were known to participants through their formal roles with the STEPS Program. The specific semistructured interview schedules (i.e., interview guides) utilised in the present study were developed by the research team based on their collective experience in conducting qualitative research and their extensive experience with the various components of the STEPS Program.
Furthermore, the schedules incorporated the guidelines proposed by Paterson and ScottFinlay (2002) concerning principles of conducting in-depth interviews with the ABI population. The specific questions included in the interview schedule are outlined in Table 1. All interviews were recorded using a digital recording device. Separate to initial rapport building and postinterview debriefing, the recorded duration of interviews with each participant was 29 minutes, 38 minutes and 21 minutes respectively.

In addition to the in-depth semistructured interviews, it also needs to be acknowledged that each participant in the present study had extensive involvement over a period of at least 2 years with STEPS Program staff. As such, the combined experiences of STEPS Program staff in directly observing and supporting each of the three participants in their roles as STEPS Program Leaders were incorporated into the case reports. The specific additional data incorporated in the case reports included the following items, which are routinely collected by STEPS Program staff in accordance with standard STEPS Program policies and procedures:

- Leader Training Evaluation Form - at the completion of the 2-day STEPS Leader Training Program, trainees complete a structured evaluation form about their training experiences.

- STEPS Skills Program Support and Supervision Summaries - during STEPS Skills Program delivery, all leaders receive weekly contact with STEPS Program staff. Staff document the content of discussions using a weekly support and supervision template.

- STEPS Skills Program Leader Evaluation Form - after leading a STEPS Skills Program, Leaders complete a structured evaluation form about their experiences of leading the group program.

- STEPS Skills Program Participant Evaluation Form - at the completion of the STEPS Skills Program, participants are asked to complete a structured evaluation form about their experiences of being a participant. The form includes information about their experiences with the leader.

- STEPS Network Group Support and Supervision Summaries - throughout the course of leading a STEPS Network Group, leaders maintain regular contact with STEPS Program staff. Staff document the content of network group discussions using a support and supervision template. 
TABLE 1

Overview of Questions Included in the Interview Guide

\begin{tabular}{ll}
\hline Content focus & Questions \\
\hline Leader experiences & Description: Please describe your involvement with the STEPS Program \\
& Reason for being a STEPS Leader: Why did you decide to become a STEPS Leader? \\
& $\begin{array}{l}\text { Experiences as leader: How have you found (did you find) the experience of being } \\
\text { a STEPS Leader? } \\
\text { Co-leadership: Please describe your experiences of co-leadership. }\end{array}$
\end{tabular}

Growth and positive change
Growth as a leader: How did being a STEPS Leader help you to grow personally?
How did being a STEPS Leader help you with your ongoing recovery from injury?

Growth of participants: What were the benefits of the program for participants? How did the program help participants grow?

Outcomes for leaders: How has being a STEPS Leader helped you to achieve goals in your life? What changes have happened in your life as a result of your involvement in STEPS? How does it feel for you to have achieved these goals/made these changes?

Outcomes for participants: What goals were you able to see participants achieve through involvement with STEPS? What changes were participants able to make in their lives as a result of being involved with STEPS? As a leader, how did it make you feel to see participants achieve these goals/make these changes?

\section{Procedure}

Ethical approval for the study was obtained from a metropolitan-based university as part of a larger research investigation that examined the effectiveness of self-managed networks of support for individuals with $\mathrm{ABI}$ and their families. Additionally, all three participants provided consent within their roles as STEPS Program Leaders in accordance with hospital policy and guidelines. After informed consent was obtained, each participant was contacted to arrange a suitable time to conduct the semistructured interview. Interviews for $\mathrm{Mr} \mathrm{A}$ and Ms B were conducted in person at the participants' homes. Due to geographical considerations, Mrs C's interview was conducted via telephone contact. Each participant received a copy of the interview schedule prior to the actual interview to facilitate greater recall and clarity of participant responses and experiences. Following the completion of the semistructured interviews, case reports including the additional summary and descriptive data were compiled by the research team.

\section{Data Analysis}

The recorded interviews were transcribed verbatim to create written transcripts of the narratives produced by participants. Data analysis entailed a four-stage process that was adapted from an approach described by Patton (2002). The specific analysis approach utilised for the present study is outlined in Figure 1.

Several strategies were used to enhance the rigour or trustworthiness of the findings, including: (1) triangulation of data sources (i.e., multiple sources of data collection to construct case narratives), (2) prolonged engagement of participant contact (i.e., all participants known to the STEPS Program for at least a 2-year period), (3) initial data analysis conducted by a member of the research team who was independent of the STEPS Program and (4) reflexivity of interview process, construction of case narratives and cross-case pattern analysis coding and theme interpretations (i.e., in-depth collaborative discussion between members of the research team including an occupational therapist, a physiotherapist and a psychologist) (Patton, 2002). These strategies were incorporated to limit the potential for researcher bias during the processes employed for data collection and analysis. The reflexivity process highlighted to the research team that the close nature of the interviewer-participant relationships aided the depth of information gathered in the process of constructing the case narratives. This, in turn, contributed to the depth of inquiry for the cross-case pattern analysis. 


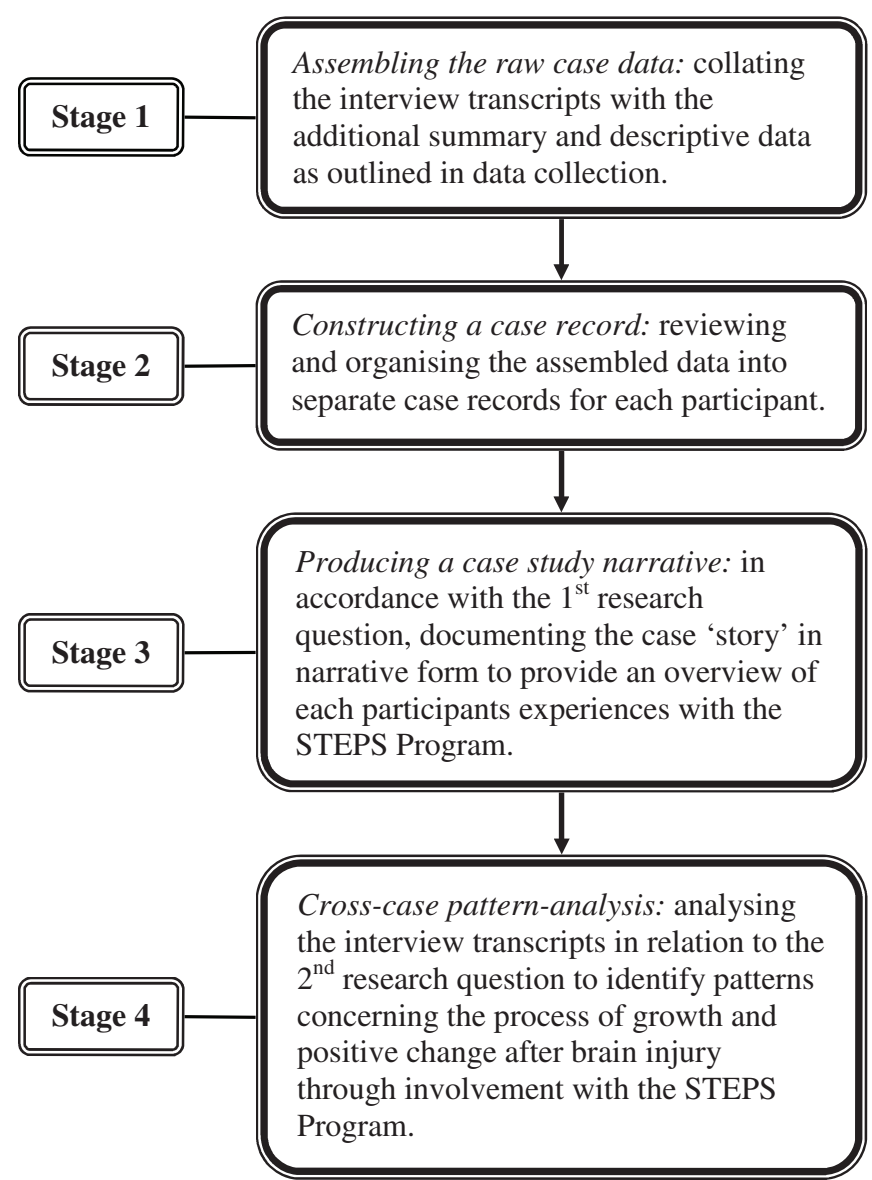

FIGURE 1

Summary of the case study data analysis process.

\section{Findings and Discussion}

\section{Case Study Narratives}

The first two stages of the data analysis process facilitated the development of the following narrative case 'stories' of each participant's journey with the STEPS Program.

\section{Participant 1}

Mr A's journey with the STEPS Program began when he was referred by a health professional in his local area to be a participant in a STEPS Skills Program. At the completion of this program, the STEPS group joined with an existing local brain injury support group, where $\mathrm{Mr}$ A became increasingly involved in group organisation and activities. Mr A went on to complete the 2-day STEPS Leader Training Program, which he described as 'a good way to get to know how I was going to react with other people'. $\mathrm{Mr} \mathrm{A}$ also reflected that being a participant in the program later assisted him as a STEPS Program Leader: 'having people come into STEPS after I had done the program myself, I could explain it easier to them'.

After completing the leader training, $\mathrm{Mr}$ A led a STEPS Skills Program with two support workers from a local lifestyle support service. In reflecting on the benefits of co-leadership, Mr A stated:

It was pretty good because we could share the responsibilities a bit, it wasn't too overbearing for me ... I get fairly tired and the [co-leaders] would see that I was a bit tired so they would take over different parts ... we all got to prop each other up if you like. 
Participants in the program co-led by Mr A provided positive feedback in the Participant Evaluation Form and the group continued to meet on a monthly basis after the completion of the STEPS Skills Program. In reflecting on the benefits of the program for participants, Mr A shared the following experience of a participant's progress towards achieving a goal through her involvement with the STEPS Program:

\begin{abstract}
She [participant] said: 'I don't really have one [i.e., a goal]' and I said: 'Aren't you playing darts?' And she said 'Yes', so I said: 'Do you want to improve on darts?' And she said, 'Yeah.' So I said: 'All right, then let's make that your goal' ... she showed up with - I think it was the second-last meeting - and she had a trophy with second most-improved dart player in her area ... for me, that was a plus for us [the group] and we all stood up and gave her a round of applause to make her feel good.
\end{abstract}

Through his involvement in the STEPS Program, $\mathrm{Mr}$ A went on to become the president of the local brain injury support group. In performing this role, $\mathrm{Mr} \mathrm{A}$. developed the idea of holding a lawn bowls day in his local community to raise awareness of brain injury. The bowls day coincided with the week 6 community activity for the STEPS Skills Program and all group participants attended. Mr A. reflected the following concerning the purpose and outcome of the bowls day:

I wanted to get awareness out there that people, hold on a minute, we've had a brain injury, but we are having a go at something ... we didn't raise a lot of money, but that's not the point, the awareness ... was the main thing.

Mr A. hopes that the bowls day will become an annual event in his local community.

\section{Participant 2}

Ms B became aware of the STEPS Program after attending a stroke support group in her local community - 'I was in a stroke support group meeting and one of the people I befriended was going to be a leader ... he handed me a pamphlet and said you should go'. She went on to be a participant in a STEPS Skills Program and reflected the following concerning her experience:

\footnotetext{
At first, it was a little daunting because even in a small group you have to be able to speak to other people and I wasn't quite up to that stage yet ... but as the sessions went on, my shyness decreased.
}

After completing the STEPS Skills Program, Ms B became an active participant in her local STEPS Network Group by assisting with planning and organising group activities. She later repeated the STEPS Skills Program for a second time, before applying to do the STEPS Leader Training Program.

After completing the leader training, Ms B coled a STEPS Skills Program in her local community with another peer leader (i.e., the same leader who led the program in which Ms B was a participant). Ms B stated: 'I found it a lot more comfortable' to be a co-leader. In reflecting on the benefits of the program for participants, Ms B commented on the friendships that were developed, the confidence gained and the social aspects of the program. Ms B shared the following experience of one participant:

\section{I've seen one lady, she had a stroke some time ago ... but I found that after the STEPS Program, her walking has improved and also her speech, she would let her husband speak for her, but now she is speaking alone ... the same couple, they're now going out more often whereas before they did STEPS they would stay at home.}

The weekly support and supervision summaries for Ms B's group reflect the social development of the group over the course of the 6-week STEPS Skills Program.

Ms B reflected that her involvement with the STEPS Program has led to personal development in other areas of her life. For example, Ms B. stated:

One thing that I found the first program I did helped me with my confidence ... it helped me indirectly with my holiday to [overseas]. It gave me confidence to travel alone ... that's a major goal of mine to be able to do something independently.

Ms B. also reflected that her increased confidence has enabled her to become more involved in other volunteer pursuits:

I became a member of the Aphasia Association and I became a member of the publicity committee and I did some group work ... and also the confidence has made it easier to speak in public, so I spoke at parliament house ... and I've also done some other public speaking, things which I don't think I'd be able to do if I didn't have the initial confidence boost.

\section{Participant 3}

Mrs C's interest in being a STEPS Program Leader developed after her son sustained a TBI. 
After a lengthy stay away from home after the onset of her son's injury, Mrs C finally returned to her home town in a rural location to find "we were virtually on our own when we went back ... there were no services there for [my son]'. Consequently, Mrs C's motivation to become a STEPS Program Leader came from her desire to help her son and others who found themselves in similar situations. In reflecting on this, Mrs C made the following statement:

I wanted to help in any way I could to support him [my son] and this program was able to give me ideas to be able to support him and ... be better equipped to deal with the community and other people.

Mrs C completed the STEPS Leader Training Program and co-led a STEPS Skills Program in her local community with another peer leader. Of her co-leadership experience, Mrs C stated: 'it's been good for me because I work full-time and just getting everything ready sometimes and contacting people ... [co-leader] has been good that way ... he's a real good support'. In further reflecting on the group, Mrs $\mathrm{C}$ noted numerous benefits for participants:

I have certainly seen a change in quite a few of the participants ... at first, people were sort of reluctant to sort of get involved ... as time went by at the regular STEPS meetings, all of the participants have come out of their shells ... and their openly talking and openly discussing, they're actually having fun and they want to come back.
Mrs C and her co-leader have gone on to develop a STEPS Network Group in their local community, which they have supported for several years now. In describing the purpose of the network group, Mrs C stated:

We meet once a month ... we do have speakers that come and talk to the participants and sometimes that includes a social worker, or the podiatrist, physiotherapist; they all come and give a talk about their services ... and we mostly do a lot of talking and support a lot.

Mrs C's involvement with the STEPS Network Group has meant that she has been able to observe the group over a long period of time. In reflecting on her involvement with the group, Mrs C stated:
It's absolutely fantastic to see these people actually smile now and actually participate in a group whereas before, they would just sit there ... there was no expression on their faces ... they've got their confidence now ... it's great to see them smiling and see that they are happy.

\section{Cross-Case Pattern Analysis}

Using a cross-case pattern analysis, two dimensions of comparison emerged, namely a process dimension and an outcome dimension. The process dimension reflects the process by which participants became STEPS Program Leaders and the outcome dimension reflects the growth outcomes that participants elucidated in their descriptions of their experiences as STEPS Program Leaders. These dimensions are consistent with the arguments proposed by Tedeschi and Calhoun (2004) suggesting

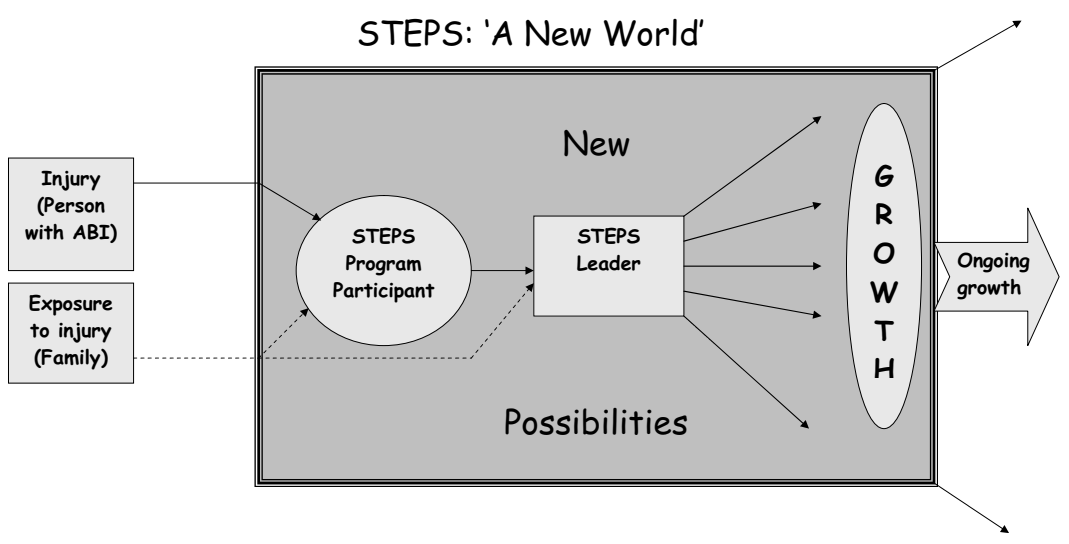

FIGURE 2

Process of growth in STEPS: 'A New World'. 
that posttraumatic growth is not only an outcome but also a process that unfolds over time.

Figure 2 diagrammatically represents the patterns in process that emerged from a comparison across cases. For both individuals with brain injury who became STEPS Program Leaders, the process began initially with participation in the STEPS Skills Program that was completed as part of efforts towards rehabilitation/recovery (returning to pre-injury self). While this process did not necessarily result in posttraumatic growth per se for these participants, it provided a forum within which skill development and successful coping emerged. This environment encouraged individuals to engage in constructive cognitive processes and facilitated the psychological preparedness necessary for posttraumatic growth (Calhoun \& Tedeschi, 2004). During this process, new possibilities for continued personal development became salient, one of which was training to become a STEPS Program Leader.

For the family member, however, new possibilities emerged through altruistic sentiments in terms of her own relative's rehabilitation and recovery and the desire to help others who sustain brain injury. While family members are invited to be participants in the STEPS Skills Program, Mrs $\mathrm{C}$ did not complete the STEPS Skills Program as a participant and instead, she elected to train as a STEPS Program Leader. The decision to become a STEPS Program Leader did, however, represent a coping strategy of social action that was used by the people with brain injury and the family member alike. An altruistic concern with helping others was integral to the decision to become a STEPS Program Leader across all cases. This pathway lends support to the role of engagement in active coping processes for posttraumatic growth (Aldwin \& Levenson, 2004; Tedeschi \& Calhoun, 2004). As Mr A stated: 'I found that doing the STEPS Program at the start it helped me a lot and that's why I wanted to be a leader to encourage other people to do the training'. Upon training to become a STEPS Program Leader and by enacting this training within the delivery of a STEPS Program, the process opened up further new possibilities in terms of leadership and taking up other social roles. The process of becoming a STEPS Program Leader recognised worth in the individual, assisted with envisioning the future and facilitated active involvement in determining that future, factors considered likely to facilitate posttraumatic growth (Turner \& Cox, 2004). This was the point at which posttraumatic growth outcomes, defined as positive changes that are greater than pre-injury (Tedeschi \& Calhoun, 2004) appeared to emerge above and beyond what was considered part of rehabilitation and recovery.

Importantly, the emergence of posttraumatic growth was considered to be the first step rather than a final end point. Janoff-Bulman (2004) suggested that by learning about oneself, individuals begin to see themselves in a different light and this is a process that continues over time. Indeed, several authors support the notion that posttraumatic growth can change and continue over time following injury or trauma (Gangstad et al., 2009; McGrath \& Linley, 2006) through the adoption of a 'growth viewpoint' (Calhoun \& Tedeschi, 2004). All leaders perceived that growth was an ongoing process and there was an expectation that they would continue to grow. In this sense, they described the STEPS Program environment as a 'new world' providing a forum within which ongoing growth could occur through learning. 'Seeing them improve it makes me feel good and I'm still learning different things from what they say ... it's a new world and you've got to open your eyes to everything that is going on' (Mr A). The importance of social systems (McMillen, 2004; Tedeschi $\&$ Calhoun, 2004) and sociocultural contexts (Pals $\&$ McAdams, 2004) in this process is widely recognised and the current findings lend support to the relevance of these contexts.

The processes of posttraumatic growth through STEPS Program Leader involvement resulted in growth outcomes in multiple domains, namely 'expansion of social roles and skills', 'appreciation of life', 'interpersonal relationships and communication', 'confidence, personal strength and accomplishment' and 'growth in self as a person'. These domains closely reflect those previously outlined by Tedeschi and Calhoun (1996, 2004) and were perceived by all individuals to arise within the context of their experience as a leader but were not necessarily causally linked to the role specifically in all cases.

Growth was seen in the 'expansion of social roles and skills', with all individuals describing the adoption of new and varied social roles that differed markedly in scope or magnitude from those they had previously held in the past. Two people described new roles as a public speaker and an advocate. Being a leader and a friend to people with brain injury was also identified as a 'growth' role by one individual. In all instances, these new social roles emerged as purposeful changes in life structure and direction that have previously been identified as important dimensions of posttraumatic growth (McMillen, 1999). Sometimes the role was completely new and in other instances, previously experienced roles (e.g., leadership) acquired new 
meaning, experiences and endeavour. Mrs C stated '[I am a] bit more confident in myself to be able to go out and be an advocate for people with acquired brain injury and stroke' while Ms B described an expansion of skills: 'It helped with public speaking quite a bit because I had to project my voice but also with confidence . . . helped me with on the spot questions and it also helped me with organisational skills'. While two people felt that they had solidified these new social roles, the other still perceived themselves to be in the exploration process. Mr A stated:

\section{After I did my first STEPS Program after that I started to do a bit of volunteer work and that was a plus. I didn't think I was up to it but after doing it, you've got to get out there and have a go.}

Individuals identified growth through an enhanced 'appreciation of life'. This emerged from involvement as a STEPS Program Leader and the different perspectives on life that this fostered. Tedeschi and Calhoun (1996) suggested that this appreciation of life emerges within changes in philosophies of life. Mr A said:

I'd like to get it out there to get people to go and do the STEPS Program. If they're not a leader, be a participant because trust me it is a plus and it gives you a different outlook on what you are doing ... you have to get out there and make things happen and with STEPS it helps you do that.

An enhanced appreciation of life was reflected in the fact that all individuals looked at life a little differently. It had made them slow down to appreciate the little things while simultaneously occupying themselves with broader life priorities. Ms B stated: 'from before I did any of the STEPS programs I wasn't so enthusiastic about anything but since I did the first program and up until now I've been enthusiastic about something'; while $\mathrm{Mr}$ A commented: 'I think it makes you look at life a bit different. It slows things down a bit everything is not such a rush.'

'Interpersonal relationships and communication' were a considerable area of growth for STEPS Program Leaders and this is perhaps not surprising given the highly interpersonal nature of the STEPS Program Leader role. Indeed, a changed sense of relationships with others was one of the key factors included in early descriptions of posttraumatic growth (Tedeschi \& Calhoun, 1996) described through increased sensitivity to other people and greater efforts directed at improving relationships. Powell et al. (2007), in their study of people with brain injury, found that social support was qualitatively identified as the most important factor in facilitating this growth at all periods following injury.

All leaders outlined growth in relationships with family members, friends, their community and strangers alike. The fact that this relationship growth did not merely occur in existing close relationships is supported by McMillen (1999), who suggested that growth can include greater satisfaction and closeness with family, community and employers alike. Leaders spoke of their growth in communication and their comfort with communication that had emerged. 'I am a lot more confident from doing the STEPS groups than what I was in the beginning. I am able to relate to people a lot more ... it's helped me personally' (Mrs C).

Interestingly, leaders perceived growth that occurred in parallel with STEPS Program participants. 'I just think I've grown with these participants and I think we have all just grown as a group now' (Mrs C). Mr A stated:

It was a bit of a boost for them that there is someone that has had the same problems, that is there helping them so it's sort of a win, win situation really, it helps me go forward as well so you see that there is benefit for yourself and also for those that do it.

Turner and Cox (2004) described the deepening of relationships that could occur in posttraumatic growth, with increased compassion and sympathy for others and greater ease at expressing emotions with those around the individual.

'Confidence, personal strength and accomplishment' was a very important area of growth. As Mrs C described:

I'm a quiet person and I don't really like to be a leader of anything .... being a STEPS Leader is something that has grown on me and it has been able to bring me out of my shell.

This emergence of growth in confidence, personal strength and accomplishment is supported in the findings of Powell et al. (2007) who found that personal skills, determination and belief in self emerged as an important growth factor among people with brain injury who had sustained their injuries many years previously. Other related factors described by their participants included self-efficacy, high self-esteem, optimism, extroversion and a problem-focused style of coping. Ms B stated: 'I found it great to come out of my shell, a better achievement than getting a job promotion. It's more of a personal gain and I think it's better for the soul'. The growth in confidence allowed individuals to take control and explore opportunities that they would never previously had considered possible. 
'Without the STEPS Program, I probably wouldn't have even tried to do what we did for the day [organise bowls day]' (Mr A).

This area of growth was reflected in a personal sense of confidence and accomplishment that was recognised not only by the leader but also by their family. 'They [family] can see the grown confidence in me and that gives them a bit more confidence' (Mr A). Indeed, Wortman (2004) suggested that it is the confirmatory evidence from family members and the social network that consolidates a conclusion of tangible posttraumatic growth rather than merely the illusion of growth held by the individual alone. Calhoun and Tedeschi (2004) highlighted that corroborating evidence from family and friends is commonly reported and suggest that this provides evidence for posttraumatic growth above and beyond mere downward comparison with others in a similar situation.

The final area of growth identified by leaders was more existential in nature, described as a 'growth in oneself as a person'. Distinct from confidence and accomplishment, this area of growth resulted from perceptions of change in self that were core to identity. Janoff-Bulman (2004) described existential reevaluation as one of three explanatory models for posttraumatic growth, placing it within a reconstruction of the individual's assumptive world. Further, it was suggested that this is perhaps the most abstract and difficult to understand and quantify area of posttraumatic growth.

What did become apparent in the findings was that individual leaders derived a great deal of personal satisfaction and pleasure from this area of growth. As Ms B stated 'it feels great and I can look back on it and see that I've grown as a person ... it feels great'; while Mrs C concurred: 'being able to take STEPS groups in the future, it seems to be that I am more positive as a person'.

\section{Limitations and Recommendations for Future Research}

While offering some insight into the opportunities for posttraumatic growth that can emerge following $\mathrm{ABI}$, the current study has several limitations that suggest the need for caution in interpretation and generalisation. The small sample size, while appropriate for case study designs, does not allow generalisation of the current findings to broader populations of people with brain injury. Indeed, the experiences of growth outlined by participants in the current study contrast with the poor social outcomes often reported in the literature. Although the participants selected were generally representative of STEPS peer/lay leaders, a larger sample is needed as are longitudinal studies that track post- traumatic growth for the population. Consequently, it is recommended that future research is necessary to continue to explore the emergence of posttraumatic growth over time for peer and lay leaders of the STEPS Program. Further exploration of outcomes for participants of the STEPS Program, including the potential for posttraumatic growth, is also recommended.

\section{Conclusion}

Posttraumatic growth is a growing area of research interest following trauma, including acquired brain injury. The current study supports posttraumatic growth as both a process and an outcome, with multifaceted domains of growth possible as a result of cognitive processing in the aftermath of coping with trauma. The study supports the breadth of these domains of growth across perceived changes in self, changed relationships with others and changed philosophies of life. What emerges from the current study, above and beyond that which is currently known, is a new understanding of how posttraumatic growth can be facilitated within a therapeutic intervention. The STEPS Program as a step in recovery from brain injury offers a pathway for individuals to enter 'a new world' as a STEPS Program Leader within which the foundations for posttraumatic growth are laid. In this world, individuals can expand their social roles and skills, develop appreciation of life, enhance interpersonal relationships and communication, develop confidence, personal strength and accomplishment and identify growth in self as a person. With the expansion of the STEPS Program and the training of new STEPS Program Leaders, both the geographic distribution and the density of the STEPS Program Network will be exponentially enhanced. The chain reaction of posttraumatic growth that potentially lies within this 'new world' remains largely unexplored but offers new avenues of hope for people that life really can improve following brain injury.

\section{Acknowledgments}

The authors gratefully acknowledge the contribution of the participants in this study. The authors also acknowledge the Griffith University Centre for Clinical Practice Innovation for their evaluation work on aspects of the STEPS Program.

\section{References}

Aldwin, C.M., \& Levenson, M.R. (2004). Posttraumatic growth: A developmental perspective. Psychological Inquiry, 15(1), 19-22. 
Calhoun, L.G., \& Tedeschi, R.G. (2004). The foundations of posttraumatic growth: New considerations. Psychological Inquiry, 15(1), 93-102.

Campbell, W.K., Brunell, A.B., \& Foster, J.D. (2004). Sitting here in limbo: ego, shock and posttraumatic growth. Psychological Inquiry, 15(1), 22-26.

Gangstad, B., Norman, P., \& Barton, J. (2009). Cognitive processing and posttraumatic growth after stroke. Rehabilitation Psychology, 54(1), 6975.

Hawley, C.A., \& Joseph, S. (2008). Predictors of positive growth after traumatic brain injury: A longitudinal study. Brain Injury, 22(5), 427-435.

Janoff-Bulman, R. (2004). Posttraumatic growth: Three explanatory models. Psychological Inquiry, 15(1), 30-34.

Linley, P.A., \& Joseph, S. (2004). Positive change following trauma and adversity: A review. Journal of Traumatic Stress, 17(1), 11-21.

Maercker, A., \& Zoellner, T. (2004). The Janus face of self-perceived growth: Toward a two-component model of posttraumatic growth. Psychological Inquiry, 15(1), 41-48.

McGrath, J.C., \& Linley, P.A. (2006). Post-traumatic growth in acquired brain injury: A preliminary small scale study. Brain Injury, 20(7), 767-773.

McMillen, J.C. (1999). Better for it: How people benefit from adversity. Social Work, 44(5), 455-468.

McMillen, J.C. (2004). Posttraumatic growth: What's it all about? Psychological Inquiry, 15(1), 48-52.
Neimeyer, R.A. (2004). Posttraumatic growth: A narrative elaboration. Psychological Inquiry, 15(1), 5359.

Nolen-Hoeksema, S., \& Davis, C.G. (2004). Theoretical and methodological issues in the assessment and interpretation of posttraumatic growth. Psychological Inquiry, 15(1), 60-64.

Pals, J.L., \& McAdams, D.P. (2004). The transformed self: A narrative understanding of posttraumatic growth. Psychological Inquiry, 15(1), 65-69.

Paterson, B., \& Scott-Finlay, S. (2002). Pearls, pith, and provocation: Critical issues in interviewing people with traumatic brain injury. Qualitative Health Research, 12(3), 399-409.

Patton, M.Q. (2002). Qualitative research and evaluation methods (3rd ed.). California: Sage.

Powell, T., Ekin-Wood, A., \& Collin, C. (2007). Posttraumatic growth after head injury: A long-term follow-up. Brain Injury, 21(1), 31-38.

Tedeschi, R.G., \& Calhoun, L.G. (1996). The Posttraumatic Growth Inventory: Measuring the positive legacy of trauma. Journal of Traumatic Stress, 9(3), 455-471.

Tedeschi, R.G., \& Calhoun, L.G. (2004). Posttraumatic growth: Conceptual foundations and empirical evidence. Psychological Inquiry, 15(1), 1-18.

Turner, S., \& Cox, H. (2004). Facilitating post traumatic growth. Health and Quality of Life Outcomes, 2(34), 1-9.

Wortman, C.B. (2004). Posttraumatic growth: Progress and problems. Psychological Inquiry, 15(1), 81-90. 